\title{
Deer industry expansion and wealth creation
}

\author{
W. J. PARKER ${ }^{1}$ and M.J. LOZA ${ }^{2}$ \\ ${ }^{I}$ Chief Operating Officer, AgResearch, Ruakura Research Centre, Hamilton \\ ${ }^{2}$ CEO, Deer Industry New Zealand, Wellington
}

\begin{abstract}
The New Zealand deer industry is projected to grow strongly over the next decade with venison and velvet production forecast by some models to increase by 16740 tonnes $(67 \%)$ and 300 tonnes $(60 \%)$, respectively, in the next four years alone. Commensurate growth in high paying markets is required to prevent these raw materials becoming commodities with associated downward pressure on prices ac hieved by the industry. Furthermore, growth in supply will generate increasing volumes of co-products, for which market opportunities need to be developed. The deer industry is thus following the classical technology $\mathrm{S}$ curve and requires further innovation to maintain wealth for its participants.

The industry has worked with research providers to develop a R\&D strategy to counter commodification, by supporting the expansion of the industry into year-round chilled venison products into niche markets and developing new enterprises from deer co-products. DEEResearch was formed to provide research direction and increase effective industry investment into $R \& D$ through better coordination of research and a combination of funding directly from the industry and additional funds leveraged from other sources. As a relatively small industry, the deer industry faces the challenge of assembling the critical mass and investment necessary to support expansion. Crown funding is critical to overcoming these constraints and the industry's progressive and united vision is important in securing this.
\end{abstract}

Keywords: Deer industry, research coordination, strategy

\section{Introduction}

The New Zealand deer industry is projected to grow strongly over the next decade (MAF 2002). This growth continues and builds from a base of 20 years of investment into deer farming, processing and marketing. Expansion has been underpinned by research and development $(R \& D)$, entrepreneurship and risk taking, and the complementary infrastructure, technology and expertise of the sheep and beef cattle industries. In 1990 the fob value of deer exports was $\$ 106 \mathrm{~m}$; by 2000 it had doubled to $\$ 215 \mathrm{~m}$. An almost trebling of earnings by 2008 to $\$ 596 \mathrm{~m}$ has been projected (MAF 2002).

These growth projections have very important implications for the deer industry if it is to avoid commodification of its core products - venison, velvet, co-products and hides - due to supply outstripping demand from existing and new markets. Already symptoms of cyclic prices to farmers are evident and it would be imprudent to rely on one-off events such as the consumer-response to BSE in beef cattle (1996-2000) to stimulate the level of sustainable demand seen as necessary to match supply. Industry development must therefore be planned and investment, particularly in R\&D, targeted to support value adding growth initiatives and productivity gains.

The purpose of this paper is to set out the implications of growth for industry participants and to suggest solutions to achieve sustainable real returns to all sectors of the industry.

\section{Growth Projections}

An industry supply model for deer products and live animals has been constructed by MAF (2002). The model utilises typical performance parameters for the national herd and expert advice on the impact of technology, climate and markets on the farmed deer population to forecast changes in supply and inventory. Statistics New Zealand census and survey data provides empirical validation of estimates, although these were not available from 1996-2001. Data from the Agricultural Production Census undertaken in 2002 is expected to be available in February 2003.

Tables 1 and 2 summarise (in 3 year time steps) forecasts of the number of deer farmed, and the tonnages of venison and velvet production arising from this. This model shows the national herd is forecast to double between 1999 and 2008. Stags represented about one third of the national herd up to 2002, and are forecast to remain at about this level through to 2008 (whether this is optimum is discussed later). The fawning percent has been relatively static over the past two decades, being $82 \%$ in 1980 and 2002(e) (Table 1). No material change in reproductive performance is anticipated through to 2008 . This suggests gains through better genetics, nutrition and health management are being mitigated by the rate of growth in herd numbers (yielding lower selection and culling pressure) and possibly by poor uptake of existing technology and best management practice ${ }^{1}$.

\footnotetext{
${ }^{1}$ Small etal. (2002) commented that the industry had no overall national strategy for technology transfer or learning, but identified successful examples such as DeerS earch, DeerMaster and DeerSouth programmes.
} 
Table 1 Statistics and projections on the population of New Zealand farmed deer.

\begin{tabular}{lrrrcc}
\hline Year & Hinds & Stags & \multicolumn{1}{c}{ Total } & Change(\%) & Fawning(\%) \\
\hline 1990 & 636,454 & 339,836 & $976,920^{1}$ & & 83.9 \\
1993 & 649,239 & 429,426 & $1,078,665^{1}$ & 10.0 & 84.6 \\
1996 & 707,428 & 484,710 & $1,192,138^{1}$ & 10.5 & 82.0 \\
1999 & $1,160,600$ & 516,190 & $1,676,790^{1,2}$ & 40.7 & 84.0 \\
2002 (e) & $1,486,640$ & 712,284 & $2,198,924^{2}$ & 31.3 & 82.0 \\
2005 (e) & $1,949,215$ & 967,391 & $2,915,606^{2}$ & 32.3 & 84.3 \\
2008 (e) & $2,578,834$ & $1,203,409$ & $3,782,273^{2}$ & 29.7 & 84.8 \\
\hline
\end{tabular}

1 Statistics NZ (various years).

2 MAF (various years).

Production and sales of venison grew strongly during the 1990s (a bout a five-fold increase). A further doubling in production and a $140 \%$ increase in venison production between 1999 and 2008 is forecast (Table 2). Venison production may grow more rapidly beyond this point if the national herd begins to stabilise. Local sales of venison, largely driven by tourism and the restaurant trade, represented just $3 \%$ of trade in 1999 and declines to about $2 \%$ in 2008. Local consumption is therefore not a material driver for industry wealth creation, although further pre-export value added processing is a large

Table 2 Historical and projected production (tonnes per annum) by New Zealand deer.

\begin{tabular}{ccc}
\hline Year & Farmed Venison & Velvet \\
\hline 1990 & 4,959 & 2741 \\
1993 & 22,250 & 4501 \\
1996 & 16,745 & 5971 \\
1999 & 25,686 & 4551 \\
$2002(\mathrm{e})$ & 27,203 & 536 \\
$2005(\mathrm{e})$ & 37,108 & 830 \\
$2008(\mathrm{e})$ & 50,217 & 940 \\
\hline
\end{tabular}

${ }^{1}$ See Table 1 for data sources.

opportunity.

Velvet production has been volatile (a range of $\pm 30 \%$ in exports 1993 to 2002) and is forecast to almost double by 2008 based on past industry trends and per stag velvet yields.

The expansion of the deer herd and increased numbers processed each year has corollary effects on the volumes of co- and by-products. These (other than skins/hides) returned $\$ 8.703 \mathrm{~m}$ (fob) in 1996 and $\$ 13.643 \mathrm{~m}$ in 2001, and could earn New Zealand around $\$ 30 \mathrm{~m}$ by 2008 .

The industry's growth exhibits the attributes of a technology $\mathrm{S}$ curve, where initial rapid expansion is followed by consolidation, and then, depending on prior investment, further expansion, incremental change or decline. These stages are illustrated in Figure 1. The deer industry is still in a rapid growth phase (ca. 10-12\% pa since 1997) but as illustrated this cannot be sustained without appropriate investment, market development and product innovation - all three of which require carefully
Figure 1 Technology yield curve showing expansion, consolidation and either further rapid expansion or incremental change (Source: Donnelly 2002).

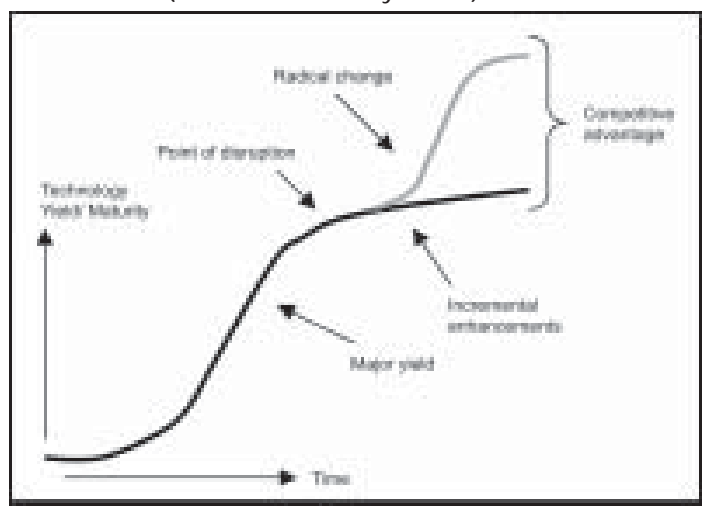

planned capital inputs and strategic leadership.

The association between growth in supply and returns is of critical interest to the industry. The total export earnings (fob) for deer products and per unit returns are presented in Table 3 . The prices in Table 3 are not corrected for exchange rate effects (see column 2) or changes in the cost of farm and processing inputs. The exchange rate has generally depreciated since 1996 providing an advantage to the industry in local currency but giving a false sense of real market returns. The popular (but not unanimous) view is that the NZ dollar will strengthen relative to major trading partners over the medium term (Greer 2002). In addition to exchange rate effects, farm inputs increased by a net $13.9 \%$ from 1993 to 2001 , with the largest increase being $5.2 \%$ in $2000-01$ and largest decrease being $-2.0 \%$ in 1998-1999 (Economic Service 2002).

Average annual returns for products (1990-2001; Table 3 ) indicate real returns (inflation adjusted) for deer products have barely been maintained over the past decade, despite the favourable exchange rate movement since 1996. To compensate for this movement, plus the effects of new technology for competing products (e.g. lambs), participants in the supply chain need to improve productivity (see later discussion). 
Table 3 Historical and projected earnings from deer products and the average nominal returns per unit of product (Source: MAF 2002).

\begin{tabular}{cccccccr}
\hline & US:NZ & \multicolumn{2}{c}{ Venison } & \multicolumn{2}{c}{ Skins \& Hides } & \multicolumn{2}{c}{ Velvet } \\
\hline Year & (\$) & fob $\$ M$ & $\$ / \mathrm{kg}$ & fob $\$ \mathrm{~m}$ & \$/skin & fob $\$ \mathrm{~m}$ & $\$ / \mathrm{kg}$ \\
\hline 1990 & .597 & 39.53 & 10.98 & 2.24 & 32.86 & 42.94 & 102 \\
1993 & .541 & 129.79 & 9.61 & 10.56 & 26.39 & 44.53 & 95 \\
1996 & .687 & 143.24 & 11.46 & 14.88 & 32.05 & 59.91 & 103 \\
1999 & .530 & 137.97 & 8.71 & 11.03 & 16.70 & 25.88 & 69 \\
2001 & .421 & 230.16 & 12.98 & 15.69 & 33.02 & 34.71 & 118 \\
2002 (e) & & 241.48 & 10.73 & 16.13 & 33.69 & 48.59 & 100 \\
2005 (e) & & 292.96 & 11.47 & 23.31 & 35.75 & 67.93 & 93 \\
2008 (e) & 456.45 & 12.11 & 33.08 & 37.57 & 76.98 & 93 \\
\hline
\end{tabular}

\section{Drivers of Demand}

Deer farmers need to keep a close eye on the primary drivers of demand for deer products. The 1990-2001 period for the New Zealand dairy industry (except the Tatua Company) illustrates how supply growth outstripped the rate of gains from new higher margin products and market development. Milk supply growth is now managed by "right to supply" shares and seasonal smoothing instruments like peak right notes (see Frampton (2002) for Tatua's supply management system). In contrast, the deer industry's or ganisational structure means it is unable to effectively introduce direct supply management. Instead it must rely on tools such as schedule pricing, forward contracts and, most critically, accurate and frequent information to producers about markets.

On the supply side the relative profitability of velvet:venison is another driver of the national herd's composition, and hence production mix. Velvet demand is concentrated on a narrow range of markets and these are highly sensitive to the per capita income of its residents and the behaviour of Northern Hemisphere competing suppliers. Until new product options for velvet are commercialised (Loza 2001), volatile returns for unprocessed velvet can be expected. The ratio of stags:hinds will reflect the fortunes of Asian economies (population and per capita income growth) but a reduction in stags to $10-15 \%$ of the national herd (from an estimated $30 \%$ currently) would markedly alter venison production capacity from existing farming resources.

A third driver for supply growth is the relative profitability of substitutable livestock enterprises: deer, beef cattle (including dairy beef) and sheep (see Parker (2001) for details on pastoral land use change 19802010). These livestock options utilise similar land labour (expertise) and capital requirements for animals (on a per stock unit basis) are comparable for sheep and deer but greater for cattle. Few farms are exclusively involved in deer production and farmers can scale their herd (and its composition) up or down in response to market outlook, profitability and personal preference.
On the demand side the primary factors influencing consumption of deer products are: changes in per capita incomes (affluent, discerning customers); growing awareness and concerns about health and wellness in aging populations (such as Hong Kong); availability of substitutes (such as lamb or other game); food safety (as vividly demonstrated by BSE for beef); animal welfare (such as for analgesics and indoor housing (Pollard 2002)) and perceptions of environmental sustainability (de Klein et al. 2002).

Venison's future profitability is strongly linked to yearround expansion in EU markets where consumers are discerning, patriotic and environmentally aware. Food retailers are 'on notice' from lobby groups such as 'Raceto-the-top' (Hughes 2002 pers. comm.) on issues such as food miles (a measure of energy efficiency from production to plate); exploitation of labour ('fair trade' in developing countries); environmental management (including biosecurity to avoid disease outbreaks such as foot and mouth in 2001 and therefore favouring 'local' is best); and animal welfare (for example animals in liarage for more than 24 hours require access to hay and water). Food safety is a 'given' - if assurance cannot be given that the product is safe and there is a mechanism for traceback to its origin - then it is becoming increasingly difficult to be a supplier into high-value food supply chains.

Deer farmers need to keep up-to-date with the drivers of their industry and be particularly discerning with respect to the PEST (Political/legal; Economic; Social and Technological) factors shaping future demand. New Zealand producers have historically had a strong supply focus, leaving the processors and marketers to sell the volumes they produce. This is characteristic of a commodity and in the past to strengthen their bargaining (counter-veiling) power, co-operatives of producers have been formed. However, as McKinsey (2002) reported, many co-operatives have been under pressure to create wealth for their members over the past decade. The reasons for this include: lack of scale (especially for commodities) or focus, inadequate access to capital to 
fund innovation and expansion, and in some instances lack of skills in international business governance and leadership. There are cooperative successes too, showing how innovation occurs and is managed within a structure is more important than structure per se (Frampton 2002). Long-term relationships between producer-processor-marketer are essential if value is to continue to be created and this necessitates clear, regular information exchange with farmers, and transparency in how value addition needs to occur within the demand chain.

\section{Productivity gains}

Productivity is the ratio of output:input (or efficiency) and can be achieved by: increasing output faster than the rate of inputs; decreasing inputs while maintaining output, or by increasing output from the same inputs. Production (total output) should not be confused with productivity, although the two may be related (e.g. the lowering of average unit costs of production through economies of scale). The typical (commodity) response to lower farmgate returns is to increase output either by expansion or intensification (or both). This can generate over-supply and only the most cost-efficient producers survive. However, those that pursue cost leadership remain exposed to technological gains by competitors for similar or substitute products (Porter 1985). They also usually supply commodities and have a high fixed:variable cost ratio (Boehjle 1992) which reduces flexibility and the ability to adopt innovations. The New Zealand deer industry exhibits some of these attributes and they would do well to reflect on the lessons of the dairy and wool industries where wealth creation has been hampered by low productivity gains relative to the erosion in terms of trade.

A formula for considering deer productivity is presented in Figure 2. The top line summarises the value of farm outputs (including inventory which may be used to defer or advance sales), while the bottom line summarises the costs associated with production. A similar formula could be derived for other steps in the supply chain.

As described earlier, productivity gains can be achieved by a variety of means (Table 4). The essence of y ear-onyear productivity gains is to do the basics well by using technology to its potential through expert management. However to keep pace with competitors and provide customers with new choices, this needs to be complemented by targeted R\&D investment which addresses knowledge gaps, develops new options and remedies for problems with existing technology and practice. Donnelly (2002) suggested investment should focus on sources of competitive advantage and be cognisant of movements by competitors.

\section{Industry R\&D}

The deer industry has a history of proactive support for R\&D and in 2001 formed DEEResearch, a joint venture between the Deer Farmers' Association, Deer Industry New Zealand and AgResearch to undertake industry good research (Loza 2002; Hawkins 2002). DEEResearch's vision recognises the dang ers of rapid supply growth and proposes investment to build value along the venison demand chain (Figure 3). Improved profitability through the development of technologies and markets for co- and by-products, including nutraceuticals, fashion and textiles, and speciality ingredients is envisaged. These developments require capital, third party intellectual property, market research, and new processing, extraction and packaging technologies. Crown investment into R\&D and early stage commercialisation (through various Foundation of Research Science and Technology (FoRST) investment funds) will only provide part of the capital necessary for industry infrastructure and expertise development. The deer industry needs to not only support current $R \& D$ (since in many respects deer farming and the processing and marketing of its production is unique to New Zealand, including the development of markets and brands), but also recognise the need for processors-marketers to retain sufficient earnings to enable reinvestment into emerging fields of business. The producers' trade-off for lower short-term returns is enhanced long-term viability and, as shown by the history of other livestock industries, failure to support this accelerates the slide into low margin commodification of product.

\section{Future challenges}

The New Zealand deer industry has a proud record of entrepreneurship and innovation (Drew 1994). These elements were critical to its early establishment and expansion. The challenges it now faces are different not only have the demographics of the market-place evolved but its own success has created the on-going challenge to expand and diversify markets that can support growth in the volumes of high margin products. There remain opportunities to leverage the innovations from other industries, such as packaging, ingredient extraction, and parallel co-products and genomic tools, but it is also clear that the industry is going to have to access more capital to ensure innovation and real returns are sustained during the next 5 years of rapid growth. Other challenges ${ }^{2}$ are to:

- sustainably improve productivity (increased

2 See Parker (2002) for an expanded discussion on similar topics in the context of the New Zealand diary industry. 
Figure 2 Elements in a deer farm Total Factor Productivity equation (Modified from: Pringle 2000).

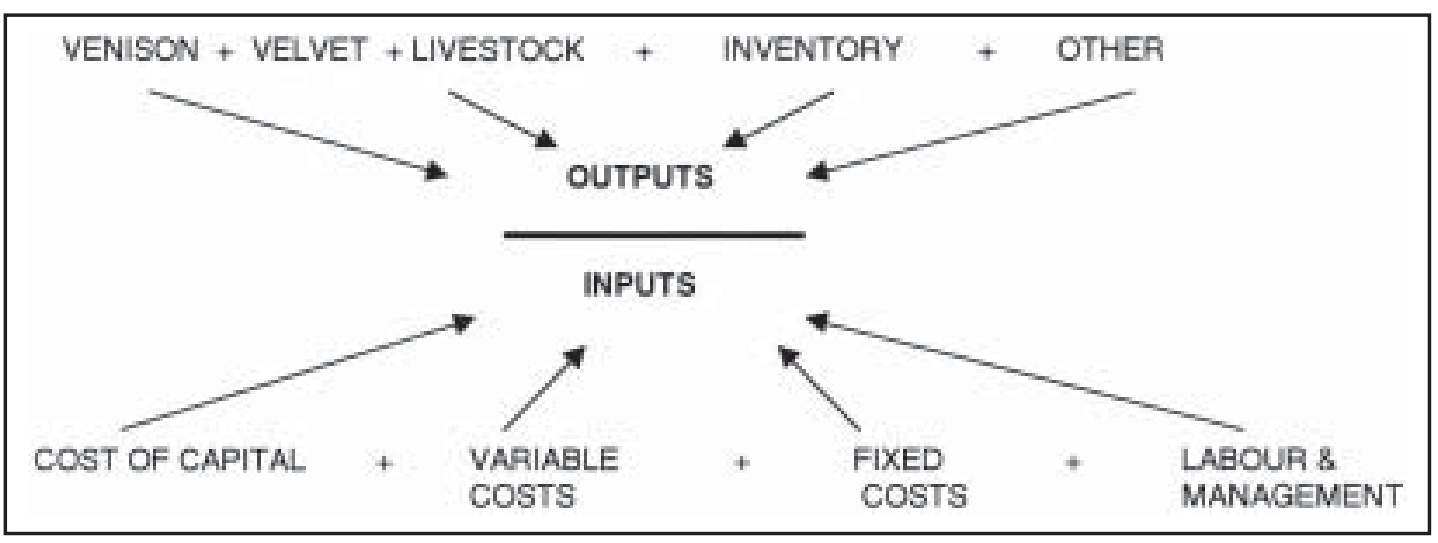

Table 4 On-farm mechanisms to achieve deer industry productivity gains (see also Drew 2002).

Productivity Parameter (see Figure 2 for context)

\section{Variable costs:}

- Optimise pasture production and utilisation

- Manage for feed quality and diet balance

- Maximise reproductive performance

- Monitor need for input and match to requirements (e.g. soil testing, faecal egg counts, blood sampling)

- Rigorously apply genetic selection and cull on performance

- Keep an up-to-date cashflow and minimise finance costs

Fixed costs and WACC:

- Minimise capital investment into plant and equipment

- Match enterprise to land value ('Don't pay too much for land')

- Invest off-farm to diversify capital base and improve returns

- Lease rather than purchase land for expansion (also equipment)

- Optimise herd composition for enterprise profitability

Labour and management:

- Achieve economies of scale on lumpy inputs like labour

- Continually upskill to improve proficiency in management

- Develop a farm business strategy with measurable objectives

- Consider labour pooling and/or use of contractors

- Improve farm layout and facility design

\section{Product volumes:}

- Maximise survival rates for all deer classes

- Maximise growth rates in young animals (minimise maintenance)

- Farm for profit, not maximum production

$\mathrm{M}$
$\mathrm{H}$
$\mathrm{H}$
$\mathrm{M}$
$\mathrm{M}$

\section{Product price:}

- Gain accreditation for QA on product (welfare, environment)

- Meet market specification by utilising scales and other measures of 'fit for purpose'

- Minimise hide damage, bruising and disease

- Strongly support investment into R\&D for high margin product innovation

- Maintain regular communication with processor-marketer and insist on accurate current and forecast market information

\section{Inventory:}

- Farm for long-term profit not short-term tax advantages

\section{Other:}

- Adopt complementary profitable enterprises (other livestock classes; farm tourism;

- Apply best management practice to natural resources (water, soils, air) 
Figure 3 Deer industry development strategy (Source: www.DEER esearch.org.nz).

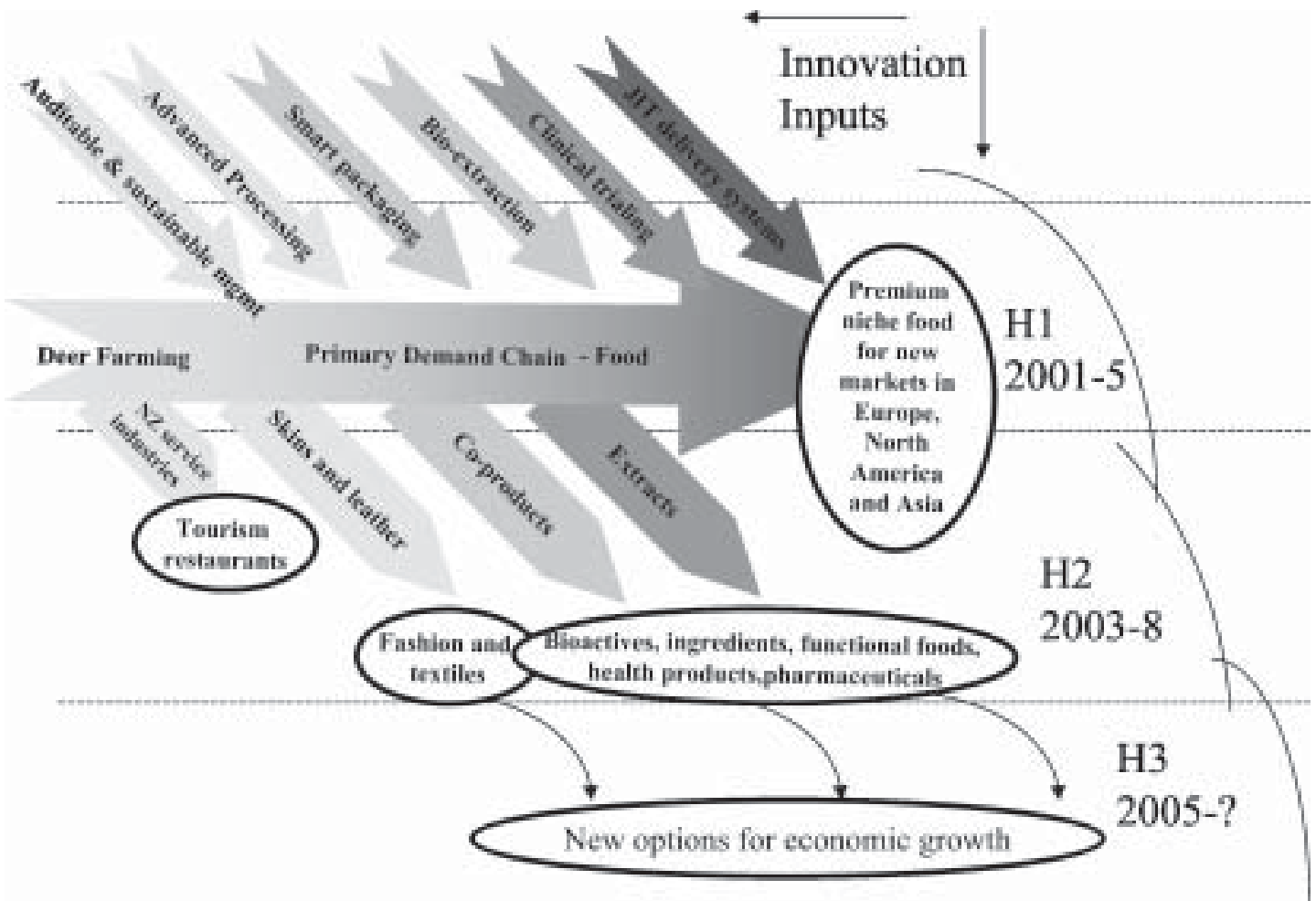

production with environmental improvement);

- develop and promote farmer leadership with experience in commerce, international trade and marketing;

- improve real returns for core products - venison, velvet, co-products and hides - through new products and markets (see Loza (2001) for velvet examples).

- attract and retain high quality labour (on-farm and along the value chain) in an increasingly competitive labour market, including between primary industry sectors (Holmes \& Cameron 2001);

- enhance energy efficiency (minimise food miles) along the demand chain.

- Manage intellectual property (IP) to constrain competitors but create value for New Zealand deer industry participants.

\section{Conclusion}

The New Zealand deer industry needs to plan and coordinate growth to avoid falling into the commodity trap and destroying long-term value for its participants. Forecasts show aggressive market development is needed to complement product development breakthroughs if anticipated extra supply is not to be sold into lower margin markets. A mix of extra capital and retained earnings will be necessary to fund this expansion and producers will need to be accepting of both if they wish to see real returns for their production improve. This and the other challenges confronting the deer industry are not dissimilar to other New Zealand pastoral-based industries, and collaboration therefore provides an important means for accessing new technology and solutions to more generic problems like environmental management, market access and the safety and traceability of products.

Deer producers have largely originated from a strong supply driven culture. They will need to be disciplined if a demand-driven, future focussed approach is to dominate industry thinking and development over the next decade. To do otherwise invites 'commodification' of the industry and ultimately the survival of only a few very large scale, cost-efficient operators.

\section{REFERENCES}

Boehlje, M.J. 1992. Cost structure and control: the dominant issues in farm management. Mimeograph, Purdue University, USA.

Burt, E. S. 2002. (ed .). Financial Budget Manual. Lincoln Univer sity, New Zealand.

de Klein, C.; Boswell, C.; Drewry, J.; McDowell, R.; Muirhead,R. 2002. Deer and the environment. Areview of current knowledge to identify knowledge gaps and research priorities. www.DEEResearch.org.nz

Donnelly, P. 2002. Boosting productivity to be competitive.ProceedingsABARE Outlook Conference, 
Canberra. www.adareconomics.com

Drew, K. 1994. Deer research - it leads the industry. Occasional Publication No. 13, (Ed. G.H. Davis), New Zealand Society of Animal Production.

Drew, K. 2002. (ed.) Deer industry productivity g rowth targets and measurement. www.DEEResearch.org.nz

Economic Service. 2002. Annual review of the New Zealand sheep and beef industry 2001-2. Economic Service, Wellington, New Zealand.

Farmers Weekly. 2001. Opinion. British Farmers Weekly (December 14): 5.

Frampton, A.F. 2002. Independent cooperatives in a deregulated New Zealand dairy industry. Dairy Farming Annual 54: Massey University. 23-30.

Greer, G.L. 2002. Market outlook for New Zealand's primary products. Special Supplement to 'Financial Budget Manual' Ed. Burt, E.S., Lincoln Univer sity.

Hawkins, B.W. 2002. New Zealand Deer Industry Conference Technical Day Conference Papers, Deer Farmers Association, Wellington, New Zealand, $10-11$.

Hughes, D. 2001. Personal communication. Professor of Food Marketing, London Imperial College, UK.

Loza, M.J. 2001. Sensitive issues for the deer industry.
New Zealand Veterinary Association Deer Branch Conference Proceedings 18: 73-78.

Loza, M. J. 2002. New Zealand Deer Industry Conference Technical Day Conference Papers, Deer Farmers Association, Wellington, New Zealand, 14-16.

MAF 2002. Forecasting Unit. MAF Policy, Wellington, New Zealand.

McKinsey 2002. A value culture for agriculture. www.mckinseyquarterly.com

Parker, W.J. 2001. Future challenges for grassland farming. Proceedings of the New Zealand Grassland Association 63: 7-15.

Parker, W.J. 2002. Meeting the challenge of future changes in New Zealand dairy farming. Dairy Farming Annual 54: Massey Univer sity. 31-40.

Pollard, J.C. 2002. Review of deer welfare. www.DEEResearch.org.nz

Porter, M. 1995. Competitive advantage. The Free Press, New York.

Pringle, R. 2000. Centre of Excellence to focus on $4 \%$ target. New Zealand Dairy Exporter 76: 84-85.

Small, B.; Botha, N. 2002. Overview of accelerated leaming and technology transfer in the deer industry. www.DEEResearch.org.nz 